\title{
DNA Microarray Analysis of Genes Differentially Expressed in Diet-Induced (Cafeteria) Obese Rats
}

\author{
Iciar P. López, Amelia Marti, Fermin I. Milagro, Maria de los Angeles Zulet, Maria Jesus Moreno-Aliaga, \\ J. Alfredo Martinez, and Carlos De Miguel
}

\begin{abstract}
LÓPEZ, ICIAR P., AMELIA MARTI, FERMIN I. MILAGRO, MARIA DE LOS ANGELES ZULET, MARIA JESUS MORENO-ALIAGA, J. ALFREDO MARTINEZ, AND CARLOS DE MIGUEL. DNA microarray analysis of genes differentially expressed in diet-induced (cafeteria) obese rats. Obes Res. 2003;11:188-194.

Objective: To better understand the molecular basis of dietary obesity, we examined adipose tissue genes differentially expressed in an obesity model using DNA microarray analysis.
\end{abstract}

Research Methods and Procedures: We assessed the expression level of over 12,500 transcripts in epididymal fat pads from (cafeteria) obese and control rats with the aid of the array technology.

Results: Cafeteria (obese) rats weighed 50\% more and had 2.5-fold higher levels of epididymal fat and elevated levels of circulating leptin. Adipose genes differentially expressed in obese and control rats were categorized into five groups: macronutrient metabolism, transcription factors, hormone receptor and signal transduction, redox and stress proteins, and cellular cytoskeleton. Interestingly, the expression levels of a number of genes involved in lipid metabolism such as glycerol-3-phosphate dehydrogenase, stearoyl coenzyme A desaturase, together with the transcription factors implicated in adipocyte differentiation (CAAT/enhancer binding protein- $\alpha$ and peroxisome proliferator-activated receptor$\gamma$ ), were significantly increased in obese animals compared with control. The most up-regulated transcripts were the $o b$

Received for review August 21, 2002.

Accepted for publication in final form November 19, 2002.

Biochemistry and Molecular Biology and Physiology and Nutrition Departments, Línea Especial Nutrition and Obesity, University of Navarra, 31080 Pamplona, Navarra, Spain Address correspondence to Dr. A. Marti, Department of Physiology and Nutrition, University of Navarra, 31008 Pamplona, Spain.

E-mail: amarti@unav.es

Copyright (C) 2003 NAASO (49.2-fold change) and the fatty acid-binding protein genes (15.7- fold change). In contrast, genes related to redox and stress protein were generally down-regulated in obese animals compared with the control.

Discussion: Our study showed that in diet-induced obesity, the expression levels of some important genes implicated in lipid metabolism were up-regulated, whereas those related to redox and stress protein were down-regulated in obese animals compared with control. This pattern of gene expression may occur in human obesity cases after high-fat intake.

Key words: DNAchip, adipose tissue, high-fat diet, gene expression

\section{Introduction}

Increased food intake and decreased energy expenditure associated to modern lifestyles have contributed to the widely spread of obesity development. However, environmental factors cannot fully explain the increasing rates of obesity prevalence $(1,2)$. In fact, genetic predisposition for obesity may underlie the tendency for weight gaining in some individuals (3). Cafeteria-fed rats represent a useful model for human obesity studies because a high-fat intake is a key factor in the development of human obesity $(4,5)$. Because the enlargement of fat deposits is led by changes in gene expression, DNA array technology, with thousands of genes examined in a single hybridization, constitutes a powerful tool to identify and compare patterns of gene expression $(1,6-8)$.

Several arrays have been conducted in genetically obese animals, providing valuable new molecular insights despite some limitations $(9-11)$. Here, we report the effects of long-term high-fat intake on the expression pattern of 4500 full-length genes. Gene expression profile of adipose tissue from obese rats (cafeteria diet) was compared with control animals to search for changes in gene expression in response to a hypercaloric fat-rich diet. 


\section{Research Methods and Procedures}

\section{Animals and Sample Preparation}

Male Wistar rats (5 weeks old) obtained from the Applied Pharmacobiology Center (University of Navarra, Spain) were selected for this study. The animals were housed in cages under controlled conditions of light (12 hours of light/12 hours of dark) and temperature $\left(22 \pm 2{ }^{\circ} \mathrm{C}\right)$. All experimental procedures were performed according to the National and Institutional Guidelines for Animal Care and Use at the University of Navarra. Rats (20) were assigned into two dietary groups for 65 days. The control group $(n=$ 10) was fed with a standard laboratory pelleted diet and free access to water ( $6 \%$ calories from fat), whereas the second group (cafeteria diet, $n=10$ ) was fed a fat-rich hypercaloric diet containing pate, chips, chocolate, bacon, biscuits, and chow in a proportion of $2: 1: 1: 1: 1: 1$ as previously published $(4,5)(65 \%$ calories from fat). Food was offered ad libitum and food intake and body weight were measured daily. After the experimental feeding period, animals were euthanized and epididymal white adipose tissue was immediately removed, frozen in liquid nitrogen, and stored at $-80{ }^{\circ} \mathrm{C}$. Serum glucose, proteins, cholesterol, glycerol, triglycerides, and free fatty acids were analyzed using an Autoanalyzer (Cobas Roche Diagnostic, Basel, Switzerland) by routine procedures. Plasma insulin was assayed by radioimmunoassay using ${ }^{125}$ I-labeled insulin (Diagnostic Products Corporation, Los Angeles, CA), whereas leptin was determined by radioimmunoassay (Linco Research, St. Charles, MO).

\section{Microarrays}

RNA Extraction. Total RNA was isolated using the Trizol RNA isolation method (Invitrogen, Carlsbad, CA) and purified with the QIAGEN RNeasy Mini Kit spin columns (QIAGEN, Valencia, CA). RNA concentration was determined spectrophotometrically and RNA integrity was confirmed on a $1 \%$ agarose gel electrophoresis.

Target Preparation. Double-stranded DNA was synthesized using the Superscript Choice System (Invitrogen). Typically, $7 \mu \mathrm{g}$ of total RNA coming from a pool of three different rats, chosen at random, was used in a reverse transcription reaction to synthesize $(-)$ strand cDNA with a primer containing poly $\mathrm{dT}$ and $\mathrm{T} 7 \mathrm{RNA}$ polymerase promoter sequences. Double-stranded cDNA was phenol-chloroform extracted followed by ethanol precipitation. The cDNA was resuspended in $12 \mu \mathrm{L}$ of RNase-free water, and $5 \mu \mathrm{L}$ of the double-stranded cDNA was used as a template for in vitro transcription in the presence of biotinylated uridine $5^{\prime}$-triphosphate and cytidine $5^{\prime}$-triphosphate to generate labeled antisense RNA. The in vitro transcription reaction was performed using the Enzo BioArray High Yield RNA Transcript Labeling Kit (Enzo Diagnostics, Farmingdale, NY). Labeled RNA was purified with the QIAGEN RNeasy Mini Kit spin columns (QIAGEN) and quantified spectrophotometrically.
Array Hybridization and Scanning. Labeled cRNA was fragmented in fragmentation buffer $(5 \times$ buffer: $200 \mathrm{mM}$ Tris-acetate, $\mathrm{pH}$ 8.1/500 mM KOAc/150 mM MgOAc) and hybridized to the microarrays in $200 \mu \mathrm{L}$ of hybridization solution containing $10 \mu \mathrm{g}$ of labeled target in $1 \times$ hybridization buffer (0.1 M Mes/1.0 M NaCl/0.01\% Tween20/20 $\mathrm{mM}$ EDTA) and $0.1 \mathrm{mg} / \mathrm{mL}$ herring sperm DNA. Test 3 arrays (Affymetrix Baracaldo, Vizcaya, Spain) were hybridized to check the cRNA integrity before the expression arrays. In all cases the GADPH $3^{\prime} / 5^{\prime}$ ratio was below 1.5. Samples were then hybridized on a Rat Genome-U34A Array (Affymetrix, Baracaldo, Vizcaya, Spain). This array contains probes derived from more than 4500 full-length or annotated genes as well as 8000 expressed sequence tag clusters. Arrays were placed on a rotisserie and rotated at 60 rpm for $16 \mathrm{~h}$ at $45^{\circ} \mathrm{C}$. After hybridization, the arrays were washed with $6 \times \mathrm{SSPE}-\mathrm{T}\left(0.9 \mathrm{M} \mathrm{NaCl} / 60 \mathrm{mM} \mathrm{NaH}{ }_{2} \mathrm{PO}_{4} /\right.$ $6 \mathrm{mM}$ EDTA/0.01\% Tween 20 ) at $25^{\circ} \mathrm{C}$ on a fluidics station (Affymetrix) for $10 \times 2$ cycles, and subsequently with 0.1 $\mathrm{M} \mathrm{Mes} / 0.1 \mathrm{M} \mathrm{NaCl} / 0.01 \%$ Tween20 at $50{ }^{\circ} \mathrm{C}$ for $4 \times 15$ cycles. The arrays were then stained with a streptavidinphycoerythrin conjugate (Molecular Probes, Eugene, OR), followed by $10 \times 4$ wash cycles. To enhance the signals, the arrays were further stained with anti-streptavidin antibody for 10 minutes followed by a 10-minute staining with a streptavidin-phycoerythrin conjugate. After $15 \times 4$ additional wash cycles, the arrays were scanned using a confocal scanner (Affymetrix).

\section{Northern Blot}

Target and $18 \mathrm{~S}$ rRNA cDNA probes were labeled by random priming (Klenow DNA polymerase I, Promega, Madison, WI) in the presence of ${ }^{32} \mathrm{P}$-deoxycytidine 5'-triphosphate $(3000 \mathrm{Ci} / \mathrm{mmol}, \mathrm{NEN}$ Life Science Products, Boston, MA). Unincorporated nucleotides were removed using Sephadex G-50 Nick Columns (Amersham Biosciences, Uppsala, Sweden). For each tissue sample, 10 $\mu \mathrm{g}$ of total RNA was fractionated by electrophoresis on a denaturing $1 \%$ agarose gel containing formaldehyde and $1 \times$ 3-( $N$-morpholino) propanesulfonic acid (MOPS) running buffer. $1 \mu \mathrm{L}$ of a $1 \mathrm{mg} / \mathrm{mL}$ ethidium bromide stock solution was added to check RNA integrity and even loading. After electrophoresis, RNA was transferred to a Hybond $\mathrm{N}^{+}$ membrane (Amersham Biosciences) overnight by capillary action and ultraviolet cross-linked (Stratalinker 1800, Stratagene, La Jolla, CA). Blots were prehybridized in $20 \mathrm{~mL}$ (Express Hyb solution, CLONTECH, Palo Alto, CA) for 45 minutes at $68^{\circ} \mathrm{C}$. Denatured labeled probe was added to the hybridization solution at a concentration of $2 \times 10^{6}$ $\mathrm{cpm} / \mathrm{mL}$ and hybridization was performed for 90 minutes at $68{ }^{\circ} \mathrm{C}$. Blots were washed three times (10 minutes) at room temperature in $2 \times$ standard sodium citrate/0.05\% SDS and two times (10 minutes) at $55^{\circ} \mathrm{C}$ in $0.1 \times$ standard sodium citrate/0.1 sodium dodecyl sulfate and exposed to X-ray 
Table 1. Weight-related and biochemical parameters in high-fat (cafeteria) diet and control animals

\begin{tabular}{lcc}
\hline & $\begin{array}{c}\text { Control } \\
\text { group }\end{array}$ & $\begin{array}{c}\text { Cafeteria } \\
\text { group }\end{array}$ \\
\hline Weight gain $(\mathrm{g})$ & $200.4 \pm 6.7$ & $289.7 \pm 14.1^{*}$ \\
Epididymal fat pad $(\mathrm{g})$ & $6.0 \pm 0.6$ & $15.3 \pm 1.8^{*}$ \\
Insulin $(\mathrm{microU} / \mathrm{mL})$ & $4.1 \pm 0.3$ & $4.5 \pm 0.8$ \\
Leptin $(\mathrm{ng} / \mathrm{mL})$ & $17.7 \pm 2.1$ & $31.4 \pm 1.6^{*}$ \\
Glucose $(\mathrm{mg} / \mathrm{dL})$ & $127.5 \pm 7.4$ & $128.5 \pm 3.2$ \\
Triglyceride $(\mathrm{mg} / \mathrm{dL})$ & $112.3 \pm 13.7$ & $117.7 \pm 14.5$ \\
Fatty acids $(\mu \mathrm{M})$ & $0.6 \pm 0.1$ & $0.60 \pm 0.1$ \\
Glycerol $(\mu \mathrm{M})$ & $173.6 \pm 8.9$ & $191.5 \pm 10.3$ \\
& & \\
Data are mean \pm SEM. & & \\
$* p<0.001, n=10$. & & \\
\hline
\end{tabular}

films with an intensifying screen for 1 day at $-80{ }^{\circ} \mathrm{C}$. To allow loading of equal mass of RNA in each well, after analysis of target mRNA using a cDNA probe followed by quantification of bands from film, the blots were reanalyzed using a probe complementary to rat $18 \mathrm{~S}$ ribosomal RNA. Target mRNA was then normalized with respect to the $18 \mathrm{~S}$ ribosomal signal.

\section{Data Analysis}

The Microarray Analysis Suite generated the comparative analysis. Distinct algorithms made an absolute call (presence/absence for each transcript), a decision about differential expression between samples: increase or decrease and the magnitude of change (represented as fold change, with a value of 1 indicating no difference). The difference decision fold and the mathematical definitions for each of the algorithms are described in the Affymetrix Microarray User's Guide (version 4.0).

\section{Results}

Rats eating the cafeteria diet for 65 days exhibited a significant increase in body weight gain $(+145 \%)$ at the end of the experimental trial as compared with control animals (Table 1). A statistically significant enlargement of epididymal white adipose pads was found in cafeteria fed rats compared with the control group $(p<0.001)$. Although plasma glucose, fatty acids, or glycerol were not markedly changed by the cafeteria diet, leptin serum levels were significantly higher in obese rats than in controls $(p<$ $0.001)$

The gene expression profile of assessed mRNA levels from epididymal fat tissue was compared among 4500 fulllength genes as well as 8000 expressed sequence tag clus- ters. About 15\% of assessed genes showed significant changes in gene expression in either direction. Of these, 416 RNAs were differentially expressed 2-fold or more in white adipose tissue RNA from obese rats; similarly, 429 RNA were underrepresented in white adipose tissue RNA from obese animals. Tables 2 and 3 supply a summary of the most representative genes implicated in energy metabolism, signal transduction, cytoskeleton, redox status, and transcription factors, which showed a different expression. The arbitrary numbers, representing an average difference (fold), are a measurement of the intensity of hybridization of a given RNA to the oligonucleotides on the array. The complete list of differentially expressed genes is available at http://www.unav.es/fyn/obesity.html.

The observed enlargement of adipose pads was followed by an increase in adipocyte gene expression of diet-induced obese animals. Specifically, fatty acid-binding protein (FABP) ${ }^{1}$ transcription factors [CAAT/enhancer binding protein- $\alpha$ and peroxisome proliferator-activated receptor- $\gamma$ $(\operatorname{PPAR} \gamma)$ ], and enzymes involved in lipid metabolism [malic enzyme, glycerol 3-phosphate dehydrogenase, stearoyl coenzyme A (CoA) desaturase, pyruvate carboxylase, and squalene synthetase] were up-regulated. Leptin, beta 3-adrenoceptor, and UCP3 expression levels in adipose tissue were also enhanced 49-, 2-, and 2-fold, respectively. We confirmed these changes in gene expression by Northern blot with independently generated RNA samples using probes corresponding to these differentially expressed genes. We observed an agreement between the methods for three representative genes: leptin, UCP3, and PPAR $\gamma$ (Figure 1).

The expression levels of a number of adipose tissue genes related to cell structure such as alpha B-crystallin, clathrin assembly protein, microtubule-associated protein $1 \mathrm{~A}$, moesin, and myelin basic protein were also increased. Furthermore, a rise in the expression of several genes involved in hormonal responses and signaling such as oxytocin, thyroid-stimulating hormone, growth hormone, and thyroid receptors (insulin-like growth factor-I, insulin receptor substyrate-3, vascular endothelial growth factor-b, extracellular signal-regulated kinase-2, adenylyl cyclase, tyrosine phosphatase, and Src homology 2 domain-containing protein tyrosine phosphotase substrate 1) was observed in dietinduced obese animals (Table 2).

In contrast, a significant decrease in genes encoding proteins responsible for xenobiotic metabolism (glutathione transferase) and stress response (metallothionein) was found in adipose tissue of obese animals. Interestingly, some genes encoding for energy metabolism enzymes such as aldehyde dehydrogenase, cytidine 5'-diphosphate-diacyl-

\footnotetext{
${ }^{1}$ Nonstandard abbreviations: FABP, fatty acid-binding protein; $\operatorname{PPAR} \gamma$, peroxisome proliferator-activated receptor- $\gamma$; CoA, coenzyme A.
} 
Table 2. Genes up-regulated by high-fat diet (cafeteria) in rat adipose tissue

\begin{tabular}{|c|c|c|}
\hline Fold & Code & Name \\
\hline \multicolumn{3}{|c|}{ Macronutrient metabolism } \\
\hline$\sim 49.2$ & D45862 & Leptin, ob \\
\hline $15.7 *$ & J02773 & Low-molecular weight FABP \\
\hline 7.3 & $\mathrm{~J} 00713$ & Carboxypeptidase-a-5 \\
\hline$\sim 6.7^{*}$ & U64451 & Short-branched chain acyl-CoA DH precursor \\
\hline$\sim 4.9$ & AF063302 & Carnitine palmitoyltransferase I beta \\
\hline$\sim 4.6^{*}$ & AF034577 & Pyruvate dehydrogenase kinase isoenzyme 4 \\
\hline 4.1 & M95591 & Squalene synthetase \\
\hline 3.3 & S69874 & FABP \\
\hline 3.2 & K03249 & Enoyl-CoA-hydratase-3-hydroxyacyl-CoA DH \\
\hline 3 & $\mathrm{AB} 002558$ & Glycerol 3-phosphate dehydrogenase \\
\hline 2.9 & AB005743 & Fatty acid transporter \\
\hline 2.8 & L07114 & Apolipoprotein B \\
\hline 2.5 & U20643 & Aldolase A \\
\hline 2.5 & M26594 & Malic enzyme \\
\hline 2.4 & M60322 & Aldose reductase \\
\hline 2.2 & S56481 & Beta 3-adrenergic receptor \\
\hline 2.2 & S81497 & Lysosomal acid lipase \\
\hline 2.2 & $\mathrm{~J} 02585$ & Liver stearoyl-CoA desaturase \\
\hline 2.2 & $\mathrm{X} 15580$ & 6-phosphofructo-2-kinase/fructose-2,6-bisphosphatase \\
\hline 2.2 & L12016 & Tricarboxylate transport protein \\
\hline 2.2 & U32314 & Pyruvate carboxylase \\
\hline 2.2 & D10354 & Alanine aminotransferase \\
\hline 2.2 & L25331 & Lysyl hydroxylase \\
\hline 2.1 & D43623 & Carnitine palmitoyltransferase I like protein \\
\hline 2 & D10655 & Dihydrolipoamide acetyltransferase \\
\hline 2 & AF035943 & Uncoupling protein-3 \\
\hline \multicolumn{3}{|c|}{ Transcription factor } \\
\hline $3.7 *$ & AB015724 & Nuclear receptor-binding factor- 1 \\
\hline $2.8^{*}$ & $\mathrm{X} 12752$ & DNA-binding protein $\mathrm{C} / \mathrm{EBP}$ \\
\hline 2.5 & S77528 & C/EBP-related transcription factor \\
\hline 2.1 & AB011365 & PPAR-gamma protein \\
\hline 2 & AF022081 & Small nuclear RING finger protein \\
\hline 2 & X13167 & NF-1-like DNA-binding protein \\
\hline \multicolumn{3}{|c|}{ Hormone receptor and signal transduction } \\
\hline$\sim 10.7^{*}$ & M96159 & Adenylyl cyclase type $\mathrm{V}$ \\
\hline 4 & S79241 & Oxytocin receptor \\
\hline $3.6^{*}$ & U93880 & Insulin receptor substrate-3 (IRS-3) \\
\hline 3 & K03045 & Retinol-binding protein (RBP) \\
\hline 2.9 & D38036 & Truncated TSH receptor \\
\hline 2.9 & Z83757 & Growth hormone receptor \\
\hline 2 & X92069 & P2X5 receptor (ATP-gated ion channels) \\
\hline 2.8 & E12286 & GM2 activator protein \\
\hline 2.7 & $\mathrm{X} 17053$ & Immediate-early serum-responsive JE \\
\hline 2.6 & S74351 & Protein tyrosine phosphatase \\
\hline $2.6 *$ & X06107 & Insulin-like growth factor I (IGF-I) \\
\hline 2.5 & M64300 & Signal-related kinase (ERK2) \\
\hline 2.4 & D85183 & SHPS-1 (protein tyrosine phosphatase) \\
\hline 2.4 & L13619 & Insulin-induced growth-response protein \\
\hline $2.4 *$ & L35767 & Very low density lipoprotein receptor \\
\hline 2.3 & S49003 & Short isoform growth hormone receptor \\
\hline 2.3 & D85435 & Protein kinase $\mathrm{C}$ delta-binding protein \\
\hline 2.2 & D89655 & Scavenger receptor class B \\
\hline 2.2 & $\mathrm{U} 21101$ & Cyclic GMP stimulated phosphodiesterase \\
\hline $2.2 *$ & J03819 & Thyroid (T3) hormone receptor \\
\hline 2 & AF022952 & Vascular endothelial growth factor B (VEGF B) \\
\hline 2 & S50461 & Signal-transducing $\mathrm{G}$ protein alpha 12 subunit \\
\hline 2 & L25633 & Neuroendocrine-specific protein \\
\hline 2 & M12492 & Type II cAMP-dependent PK regulatory subunit \\
\hline \multicolumn{3}{|c|}{ Cellular cytoskeleton } \\
\hline$\sim 4.9 *$ & K00512 & Myelin basic protein \\
\hline$\sim 4.0^{*}$ & AF004311 & Moesin \\
\hline 3.5 & X60351 & Alpha B-crystallin \\
\hline 3.1 & AF041373 & Clathrin assembly protein short form \\
\hline 2.7 & U50717 & Synaptic density protein PSD-93 \\
\hline 2.5 & M83195 & Microtubule-associated protein $1 \mathrm{~A}$ \\
\hline 2.3 & U75929 & Secreted protein acidic rich in cisteine (SPARC) \\
\hline
\end{tabular}

*Corresponds to a transcript absent in the control group (basal line). 
Table 3. Genes down-regulated by high-fat diet (cafeteria) in rat adipose tissue

\begin{tabular}{|c|c|c|}
\hline Fold & Code & Name \\
\hline \multicolumn{3}{|l|}{ Macronutrient metabolism } \\
\hline-22.5 & AF001898 & Aldehyde dehydrogenase (ALDH) \\
\hline$-22.1 *$ & AB009999 & CDP-diacylglycerol synthase \\
\hline$\sim-20.0 *$ & AB017260 & High-affinity carnitine transporter \\
\hline$-19.0 *$ & D37920 & Squalene epoxidase \\
\hline-9.1 & L25387 & Phosphofructokinase $\mathrm{C}$ \\
\hline$\sim-6.4^{*}$ & AB010428 & Acyl-CoA hydrolase \\
\hline-6.0 & S68135 & GLUT1 \\
\hline-3.8 & M18467 & Aspartate aminotransferase \\
\hline-2.9 & AF080468 & Glycogen storage disease type $1 \mathrm{~b}$ protein \\
\hline-2.8 & S49760 & Diacylglycerol kinase \\
\hline-2.6 & X04979 & Apolipoprotein E \\
\hline-2.4 & M93297 & Ornithine aminotransferase \\
\hline-2.2 & L07736 & Carnitine palmitoyl-transferase I \\
\hline \multicolumn{3}{|l|}{ Redox and stress proteins } \\
\hline-7.8 to $-34.1^{*}$ & S82820 & Glutathione S-transferase Yc2 subunit \\
\hline-4.8 to -6.2 & X62660 & Glutathione S-transferase subunit 8 \\
\hline-4.2 & M11794 & Metallothionein-2 and metallothionein-1 \\
\hline-2.6 to -3.2 & X02904 & Glutathione S-transferase P subunit \\
\hline \multicolumn{3}{|l|}{ Transcription factor } \\
\hline-25.2 & U78102 & Krox20 6 EGR-2 (early growth response protein 2) \\
\hline-5.2 & X94246 & Pax-8 protein \\
\hline-2.7 & M91802 & Homeobox protein (Hox 1.11) \\
\hline \multicolumn{3}{|c|}{ Hormone and signal transduction } \\
\hline-117.5 & S49491 & Proenkephalin \\
\hline$\sim-92.3^{*}$ & J04488 & Prostaglandin D synthetase \\
\hline$\sim-47.3$ & D63772 & Neuronal high affinity glutamate transporter \\
\hline$\sim-8.6^{*}$ & M12450 & Vitamin D binding protein \\
\hline-4.1 & U57715 & FGF receptor activating protein FRAG1 \\
\hline-2.8 & U48596 & MAP kinase kinase kinase 1 (MEKK1) \\
\hline-2.3 & L06096 & Inositol triphosphate receptor subtype 3 (IP3R-3) \\
\hline-2.3 & U53184 & Estrogen-responsive uterine \\
\hline-2.3 & X59132 & Secretin receptor \\
\hline-2.2 & D64045 & Phosphatidylinositol 3-kinase p85 alpha subunit \\
\hline-2.1 & AF014009 & Acidic calcium-independent phospholipase A2 \\
\hline-2 & M91599 & Fibroblast growth factor receptor subtype 4 \\
\hline \multicolumn{3}{|l|}{ Cellular cytoskeleton } \\
\hline$\sim-21.4^{*}$ & X81448 & Keratin 18 \\
\hline$\sim-12.2 *$ & M93638 & Keratin 5 \\
\hline$\sim-6.6^{*}$ & AF013247 & Beta-A4 crystallin \\
\hline$\sim-3.8^{*}$ & M59936 & Connexin-31 \\
\hline-3.2 & X67788 & Ezrin p81 \\
\hline-2.3 & X81449 & Keratin 19 \\
\hline
\end{tabular}

*Corresponds to a transcript absent in the obese group (basal line). 
A
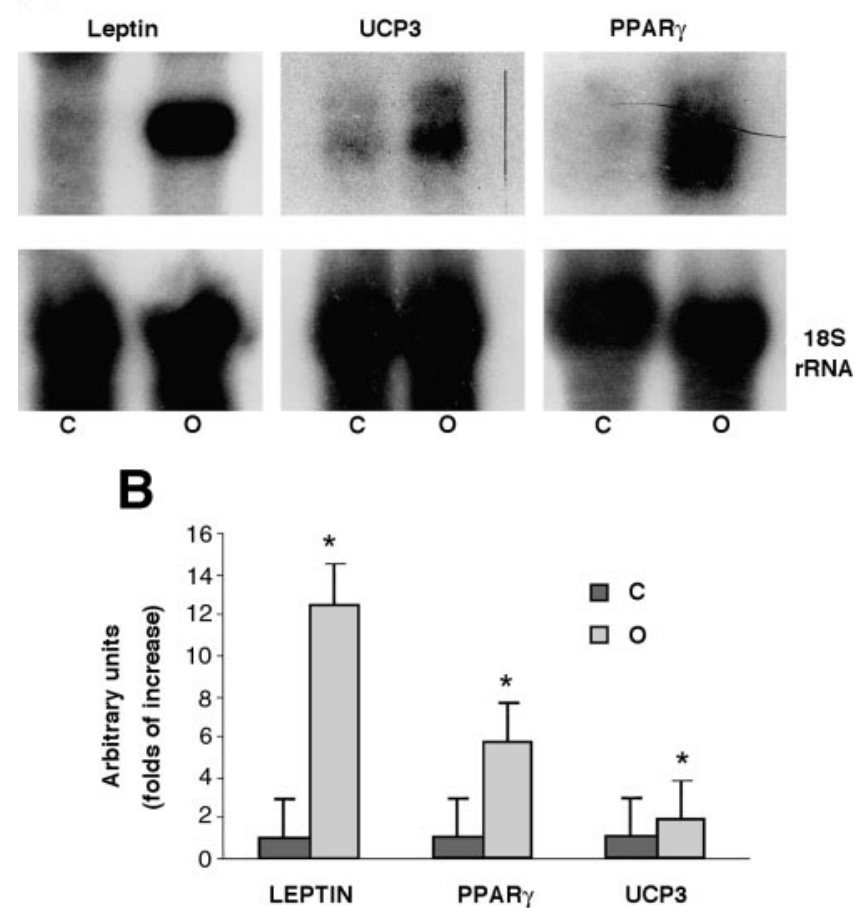

Figure 1: (A) Northern-blot analysis of the expression of leptin, $\operatorname{PPAR} \gamma$, and UCP3 in rat epididymal adipose tissue. C corresponds to control rats and $\mathrm{O}$ corresponds to obese rats. (B) Quantification of normalized values with respect to the $18 \mathrm{~S}$ ribosomal signal. Data (mean \pm SEM) are expressed as fold of increase of control rats $(n=3) .(*) p<0.05$ compared with control (Student's $t$ test).

glycerol synthase, phosphofructokinase $\mathrm{C}$, diacylglycerol kinase, together with the secreted protein, apolipoprotein $\mathrm{E}$, or the glucose transporter (GLUT1) were also down-regulated in obese rats. A similar change was also observed in genes encoding for homeobox protein and pair box 8 protein (Pax-8) and for several cytoskeleton-related proteins (keratin, ezrin, and connexin) (Table 3).

\section{Discussion}

Our study provides, apparently for the first time, insights into the molecular events implicated in epididymal adipose tissue growth after long-term cafeteria feeding with the aid of microarray technology. The expression levels of some important genes implicated in lipid metabolism are upregulated, whereas others related to redox and stress protein were down-regulated in obese animals compared with control. This model of dietary obesity is useful in the characterization of the molecular mechanisms implicated in human obesity, because many human obesity cases are thought to occur as a consequence of high-fat diets.

Previously, our group and other investigators have reported a number of adipose tissue genes (UCPs, FABP, and
PPAR $\gamma$ ) whose expression is modified by adiposity in a time-dependent fashion $(12,13)$. In this regard, high-fat feeding for short time periods significantly reduced UCP3 mRNA expression, but in contrast, a longer period of the high-fat diet raised UCP3 expression over the control diet. Similarly, short periods of dietary changes (fat elevation) down-regulate PPAR $\gamma$ levels, perhaps to avoid an excess of new adipocyte appearance, whereas the maintenance of high-fat feeding over longer time periods modifies white adipose tissue, possibly through PPAR $\gamma$-induced adipocyte differentiation (12).

However, with the gene-by-gene approach it would be difficult and time-consuming to obtain a global picture of gene patterns, because over 250 markers linked to obesity have been identified so far (14). cDNA array technology allows the comparison of thousands of mRNAs from a given tissue at once, and provides a comprehensive assessment of expression levels, representing a powerful strategy for research in the obesity field $(1,15,16)$.

The application of microarray technology regarding investigations in human diseases is growing. Recently, this approach has been applied to identify genes related to cancer, hypertension, inflammatory bowel disease, rheumatoid arthritis, and insulin resistance among others (1,17-20). In regard to obesity, two microarrays have assessed changes in gene expression in genetically obese animals (ob/ob mice). Nadler et al. (9) found that genes involved in adipocyte metabolism such as glycerol-3-phosphate dehydrogenase and stearoyl CoA desaturase were significantly decreased in $o b / o b$ mice. Similar results were reported by Soukas et al. (10) in $o b / o b$ mice. These analyses were performed in early-onset obese animals with severe metabolic diabetes and reproductive abnormalities. They are leptin-deficient, so that appetite goes unchecked and energy expenditure is low.

In the current investigation, we analyzed the expression level of over 12,500 transcripts in epididymal fat pads of control and (cafeteria) obese rats. The expression levels of adipose genes such as glycerol-3-phosphate dehydrogenase, stearoyl CoA desaturase, FABP, and UCP3, together with transcription factors (CAAT/enhancer binding protein- $\alpha$ and PPAR $\gamma$ ) were increased in these obese animals. The diet-induced obese animals had, contrary to what happens in $o b / o b$ mice, late-obesity onset due to the influence of environmental factors. As suggested by Tschop et al. (21), they represented the most appropriate animal model to study obesity compared with other models (genetically engineered animals, mechanical intervention, etc.).

Our findings are in agreement with those reported by Soukas et al. (11), concerning the higher expression of adipogenic genes during the process of adipogenesis. Furthermore, an increase in glycerol-3-phosphate dehydrogenase and stearoyl CoA desaturase gene expression levels was reported after short-term high-fat intake in rat epidid- 
ymal pads using cDNA subtraction screen (22). However, differences in gene expression may be attributed to animal species, age of animals, fat pad source, duration of fat intake, percentage of energy from fat, and so on.

In summary, our study showed that in diet-induced obesity the expression levels of important genes implicated in lipid metabolism are up-regulated whereas redox and stress protein related genes were down-regulated in obese animals compared with the control. This pattern of gene expression may occur in human obesity cases after high-fat intake.

\section{Acknowledgments}

This work was supported by the Navarra Government (Departamento Educación) and by the University of $\mathrm{Na}$ varra (LE-97 Obesidad). The technical support of Medplant (Bilbao, Spain) is gratefully acknowledged. I.L. is a predoctoral fellow funded by the Navarra Government.

\section{References}

1. Moreno MJ, Martí A, García-Foncillas J, Martínez JA. DNA hybridization arrays: a powerful technology for nutritional and obesity research. Br J Nutr. 2001;86:119-22.

2. Levin BE. The obesity epidemic: metabolic imprinting on genetically susceptible neural circuits. Obes Res. 2000;8: 342-7.

3. Marti A, Miguel C, Jebb SA, et al. Methodological approaches to assess body-weight regulation and aetiology of obesity. Proc Nutr Soc. 2000;59:405-11.

4. Berraondo B, Marti A, Duncan JS, Trayhurn P, Martinez JA. Up-regulation of muscle UCP2 gene expression by a new $\beta 3$ adrenergic agonist, trecadrine, in obese (cafeteria) rodents, but down-regulation in lean animals. Int J Obes. 2000;24: $156-63$

5. Berraondo B, Martinez JA. Free fatty acids are involved in the inverse relationship between hormone-sensitive lipase (HSL) activity and expression in adipose tissue after high-fat feeding or beta3-adrenergic stimulation. Obes Res. 2000;8: 255-61.

6. Brown PO, Botstein D. Exploring the new world of the genome with DNA microarrays. Nat Genet. 1999;21:33-7.

7. Duggan DJ, Bittner M, Chen Y, Meltzer P, Trent $\mathbf{M}$. Expression profiling using cDNA microarrays. Nat Genet. 1999;21:10-4.

8. Hacia JG. Resequencing and mutational analysis using oligonucleotide microarrays. Nat Genet. 2000;21:42-7.
9. Nadler ST, Stoehr JP, Schueler KL, Tanimoto G, Yandell BS, Attie AD. The expression of adipogenic genes is decreased in obesity and diabetes mellitus. Proc Natl Acad Sci USA. 2000;97:11371-6.

10. Soukas A, Cohen P, Socci ND, Friedman JM. Leptinspecific patterns of gene expression in white adipose tissue. Genes Dev. 2000;4:963-980.

11. Soukas A, Socci ND, Saatkamp BD, Novelli S, Friedman JM. Distinct transcriptional profiles of adipogenesis in vivo and in vitro. J Biol Chem. 2001;276:34167-74.

12. Margareto J, Gomez-Ambrosi J, Marti A, Martinez JA. Time-dependent effects of a high-energy-yielding diet on the regulation of specific white adipose tissue genes. Biochem Biophys Res Commun. 2001;283:6-11.

13. Ribot J, Felipe F, Bonet ML, Palou A. Changes of adiposity in response to vitamin A status correlate with changes of PPAR gamma-2 expression. Obes Res. 2001;9:500-9.

14. Rankinen T, Perusse L, Weisnagel SJ, Snyder EE, Chagnon YC, Bouchard C. The human obesity gene map: the 2001 update. Obes Res. 2002;8:89-117.

15. Nadler ST, Attie AD. Please pass the chips: genomic insights into obesity and diabetes. J Nutr. 2001;131:2078-81.

16. Gabrielsson BL, Carlsson B, Carlsson LMS. Partial genome scale analysis of gene expression in human adipose tissue using DNA array. Obes Res. 2000;8:374-84.

17. Aitman TJ, Glazier AM, Wallace CA, et al. Identification of Cd36 (Fat) as an insulin-resistance gene causing deflective fatty acid and glucose metabolism in hypertensive rats. Nat Genet. 1999;21:76-83.

18. Roberts M, Geiger W, German B. The revolution in microanalytic chemistry: a macro-opportunity for clinical nutrition. Am J Clin Nutr. 2000;71:434-7.

19. Jiang Y, Harlocker SL, Molesh DA, et al. Discovery of differentially expressed genes in human breast cancer using subtracted cDNA libraries and cDNA microarrays. Oncogene. 2002;21:2270-82.

20. Agostini C, Miorin M, Semenzato G. Gene expression profile analysis by DNA microarrays: a new approach to assess functional genomics in diseases. Sarcoidosis Vasc Diffuse Lung Dis. 2002;19:5-9.

21. Tschop M, Heiman ML. Rodent obesity models: an overview. Exp Clin Endocrinol Diabetes. 2001;109:307-19.

22. Li J, Yu X, Pan W, Unger RH. Gene expression profile of rat adipose tissue at the onset of high-fat-diet obesity $\mathrm{Am} \mathrm{J}$ Physiol Endocrinol Metab. 2002;282:E1334-41. 